Portland State University

PDXScholar

2016

\title{
Animal Hoarding: An In Depth Look at the Issues and Interventions
}

Amanda Mooneyham

Portland State University

Follow this and additional works at: https://pdxscholar.library.pdx.edu/honorstheses Let us know how access to this document benefits you.

Recommended Citation

Mooneyham, Amanda, "Animal Hoarding: An In Depth Look at the Issues and Interventions" (2016).

University Honors Theses. Paper 297.

https://doi.org/10.15760/honors.303

This Thesis is brought to you for free and open access. It has been accepted for inclusion in University Honors Theses by an authorized administrator of PDXScholar. Please contact us if we can make this document more accessible: pdxscholar@pdx.edu. 
Animal Hoarding: An In Depth Look at the Issues and Interventions

by

Amanda Mooneyham

An undergraduate honors thesis submitted in partial fulfillment of the requirements for the degree of Bachelor of Arts/Science in

University Honors

and

The Community Development Program

Thesis Adviser

Rita Sumner

Portland State University Year

2016 
Amanda Mooneyham

Undergraduate Honors Thesis

Spring 2016

\section{Research Question:}

How can current intervention strategies in regard to animal hoarding in 501(c)(3) nonprofit agencies inform public policy to enable prevention of new cases and reduce rates of recidivism?

\section{An Overview of Animal Hoarding}

\section{What is the scope and depth of the problem?}

Companion animals are a part of over $65 \%$ of households currently in the United States and that trend does not seem to be declining any time soon. According to the latest survey done by The American Pet Products Association, dogs and cats make up the top two most popular choice for a pet, with roughly 163.6 million currently living in homes. Currently animals are considered property under the law and with that label has come a slow progression towards legal protections for animal (Francione, 1996). Gary Patronek, VMD reports that current animal abuse cases are categorized as either direct abuse or purposeful neglect and that:

From a pragmatic perspective, community-based animal cruelty involving companion animals and encountered by humane officers employed by animal shelters has traditionally been distilled into two general types-cruelty arising from neglect that is unintentional (passive), lacks a deliberate component, and represents sins of omission; and 
cruelty that is both deliberate and intentional, involving commission of specific acts.

Animal hoarding intersects abuse and neglect and because intent is difficult to prove most animal hoarding cases are not taken as seriously as they need to be. (Patronek, 2008, 225)

Hoarding cases are not only the consequence from individuals acquiring too many animals in their private homes, but also from people operating as a 501(c)(3) status animal rescue/sanctuary. There is a growing number of animal hoarding cases coming from organizations masquerading as legitimate rescues, many registered as a 501(c)(3) nonprofit organizations and allowed to reap the financial benefits of the nonprofit status. According to Dr. Randall Lockwood, ASPCA's senior vice president of forensic sciences and anti cruelty projects, rescues and shelters now make up $25 \%$ of the estimated 6,000 new hoarding cases reported in the U.S. each year (Manning, 2011).

Rescue hoarders are a new category of animal hoarder that will require an interdisciplinary approach in order to reduce the number of new animal hoarding cases and reduce the rate of recidivism. In 2006, The Hoarding Animal Research Consortium (HARC) ${ }^{1}$ published a manual analyzing animal hoarding. HARC offers a set of characteristics of a Rescue Hoarder that might help professionals (e.g. psychologists, judges, and prosecutors) that are assigned to a hoarding case know which intervention methods would be most appropriate (20):

- has strong sense of mission to save animals which leads to unavoidable compulsion,

- fears death (of animals and self) and opposes euthanasia, 
- starts with adequate resources for animal care,

- acquires animals actively rather than passively;

- believes he/she is the only one who can provide adequate care; the initial rescue-followed-by-adoption pattern is replaced by rescue-only care.

- numbers of animals gradually overwhelm capacity to provide minimal care.

- finds it hard to refuse requests to take more animals, and

- avoids authorities and/or impedes their access

- is not necessarily socially isolated; and may work with an extensive network of enablers and be more engaged in society, therefore less amenable to intervention via social services.

According to HARC understanding the motivations of the hoarder is necessary to know what intervention methods will be most successful and what strategy to use when trying to deescalate or resolve a hoarding situation. For example, HARC suggests prosecution might be necessary for a rescue hoarder operating a nonprofit overcapacity while an overwhelmed caregiver living alone might be able to be persuaded to adopt out animals through a verbal agreement (21). Mental health evaluations along with civil and criminal interventions play key roles once an animal hoarder has been identified, however most public agencies ${ }^{2}$ are currently underutilized and oftentimes misdirected in approaching the complexities of animal hoarding cases, which is leading to high recidivism. Animal welfare agencies ${ }^{3}$ play an important role by working with local government to increase the penalties for offenders and increase protections for animals, but most states still do not recognize animal hoarding as a separate issue that 
needs to be addressed with legislative action. HARC reported on some of the current barriers to properly addressing animal hoarding in communities as follows:

In spite of the frequency and cost of these cases, most communities are woefully unprepared to handle animal hoarding cases effectively once they occur, and few, if any, have any preventive strategies in place. Because the implications of animal hoarding for human health and welfare are not widely appreciated, these cases are frequently left to animal shelters and humane societies to resolve through prosecution for cruelty to animals. Ignoring the multi-faceted nature of animal hoarding, this approach often fails, which results in almost complete recidivism. (1)

Animal welfare organizations such as Best Friends Animal Society ${ }^{4}$ and the Humane Society of the United States offer examples of "best practices" for operating a legitimate animal rescue, which in combination with examples from the states leading in animal protection laws, offers a framework for stronger measures that could serve to reduce the number of new hoarding cases and the rate of recidivism.

In order to address the research question this paper examines the following:

- the characteristics of animal hoarders, specifically rescue hoarders and the elements that contribute to new hoarding cases resulting high recidivism rate ;

- the role mental health evaluations and mental health professionals have when animal hoarding cases are prosecuted;

- $\quad$ the judicial (i.e. civil and criminal) interventions currently used; 
- best practices extracted from successful and transparent animal nonprofits (e.g. Best

Friends Animal Society and The Humane Society of the United States) and progressive legislation (i.e. Illinois and Hawaii); and

- finally, design and implementation recommendations for improving protections for animals against hoarding which will benefit animals in a non profit organization.

\section{The Characteristics of an Animal Rescue Hoarder}

\section{Recognizing Animal Hoarding as Abuse}

The animal welfare community ${ }^{5}$ is struggling to recognize the severity of animal hoarding in registered rescues and sanctuaries because of the complicated nature of most hoarding cases. Gary Patronek, VMD writes in The International Handbook of Animal Abuse and Cruelty: Theory, Research, and Application, on the need to see animal hoarding as the third dimension of animal abuse and should be taken just as seriously as an abuse case (221). Animal hoarding is categorized by contradictory interactions with the animals, i.e., simultaneously trying to save them while neglect is happening. Unlike direct and deliberate animal abuse, hoarding is often enabled because many people in positions of authority who respond to an animal hoarding case do not see the threat of hoarding as a mental illness. Now with the growing rise of hoarding cases coming from registered 501(c)(3) animal rescues and sanctuaries, there has been a shift within the animal welfare community to recognize the severity of animal hoarding originating from rescue hoarders and its effects on the animals and the community at large. The animals are not the only victims in a hoarding case as dependents living in the house also affected by the toxic environment. Adult Protective Services, Child Protective Services, and Public Health officials are potential stakeholders in a hoarding case 
depending on the circumstances. In one 1999 study of animal hoarding cases over $60 \%$ of cases surveyed involved government agencies (e.g. public health, child welfare, fire, and sanitation) and this takes a negative toll on communities health and economies (Patronek, 86).

\section{Common Personality Traits and Environmental Conditions of Animal Rescue Hoarders}

Since animal hoarding is not well understood or easily recognized, many times animal hoarders are difficult to identify especially if they are operating under the pretense of a legitimate non profit rescue or sanctuary. Private animal hoarders, whom HARC categorizes as the "overwhelmed caregiver", have been commonly stereotyped as older single women and while that may be true for individual cases of animal hoarding, the reality is that rescue hoarders make up a much more diverse background. When Gary Patronek evaluated the demographics of individual headers that fit the overwhelmed caregiver type of hoarder in cases in the 1999 study "Hoarding of Animals: An Under-Recognized Public Health Problem in a Difficult to Study Population", the cases he examined fell between 1992-1996 and found that the " . . results are in agreement with other reports that animal hoarders tend to be female, older, and solitary, to concentrate on one or two species of animal, and to fail to acknowledge the extent of the lack of sanitation and animal suffering (87).

However, since the publication of this study over 15 years ago there has been a dramatic rise in rescue hoarding cases, an increase that challenges us to re-evaluate the accepted demographics of animal hoarders. Since the demographics of rescue hoarders are not clearly understood it is necessary to identify rescue hoarding by environmental conditions. According to the HARC 2006 report there are four main characteristics of an animal hoarding situation (1): 
1. failure to provide minimal standards of sanitation, space, nutrition, and veterinary care for the animals;

2. inability to recognize the effects of this failure on the welfare of the animals, human members of the household, and the environment;

3. obsessive attempts to accumulate or maintain a collection of animals in the face of progressively deteriorating conditions; and

4. denial or minimization of problems and living conditions for people and animals.

Many times rescue hoarders will make excuses for the number of animals in their care, regardless of condition, because the rescue follows a "no-kill" philosophy ${ }^{6}$. However, reputable rescues with a "no-kill" policy will still adopt out animals and have a plan for humane euthanization when deemed medically necessary. In the 2006 HARC report, the authors touch on the issue of "no-kill"shelters in regards to animal hoarding, as stated in the document:

... these shelters must necessarily limit their intakes to available space. People who promise otherwise may, in fact, be hoarders, or on their way to becoming hoarders. Many well-run limited admission shelters exist, but, unfortunately, masquerading as a "no-kill" shelter or sanctuary is becoming an increasingly common tactic among some hoarders to establish a semblance of legitimacy. (6) 
According to the webinar in 2011 by Randall Lockwood of the ASPCA, which offers literature on starting one's own rescue and the "best practices" one should follow, here are some warning signs that a rescue or sanctuary is hoarding animals vs a legitimate rescue as compared in the following table(10):

"Legitimate Rescue Groups vs. Rescue Hoarders"

\begin{tabular}{|l|l|l|}
\hline [Resources of Rescue] & Legitimate Rescue & Rescue Hoarder \\
\hline Number [of Animals] & Known, Manageable & $\begin{array}{l}\text { Often unknown, } \\
\text { overwhelmed }\end{array}$ \\
\hline Intake [Policy] & $\begin{array}{l}\text { Limited, Selective, Often } \\
\text { Discouraged }\end{array}$ & $\begin{array}{l}\text { Unlimited, actively seeks new } \\
\text { animals }\end{array}$ \\
\hline Placement [Policy] & Actively seeks to re-home & $\begin{array}{l}\text { Usually avoids any } \\
\text { placement }\end{array}$ \\
\hline Breeding & $\begin{array}{l}\text { Most animals s/n or } \\
\text { separated to prevent } \\
\text { breeding }\end{array}$ & $\begin{array}{l}\text { Accidental or even intentional } \\
\text { breeding is common }\end{array}$ \\
\hline Funding & $\begin{array}{l}\text { Often diverse sources, } \\
\text { usually non-profit }\end{array}$ & $\begin{array}{l}\text { Often self-supported, but } \\
\text { may have non-profit status or } \\
\text { exploit "angels" }\end{array}$ \\
\hline Staff & Adequate, stable may have & $\begin{array}{l}\text { Inadequate, family, transient } \\
\text { volunteers }\end{array}$ \\
\hline offense History & None if any \\
\hline Vare & Inade & Often has previous charges \\
\hline
\end{tabular}




\section{The Contributing Factors to Animal Rescues Hoarding}

In order to start an animal nonprofit there are a few documents that one needs to file including the rescue's articles of incorporation to the state secretary's business office, application(s) for a business license and a kennel license if animals are being kept on the property, then finally submit paperwork to the IRS to obtain tax exempt status. (Dwilson, Demand Media). Kristen Pariser's 2014 article “Detailed Discussion of the Laws Regulating Rescue and Foster Care Programs for Companion Animals" reports that if a state or local government has adequate resources for an animal welfare inspector ${ }^{7}$ then some rescues are able to be randomly evaluated on site, however in most places there are only a handful of inspectors which means that random inspections are infrequent and many rescues are left without proper oversight from the state (1). Pariser expounds on the ineffectiveness of the current legal system to adequately regulate rescues, pointing out that:

The lack of laws signify that the groups are not subject to inspections nor do they have a mandated minimum set of standards of care for the animals. This means that the rescues and fosters are functioning on an honor system. In some areas of the country, rescues will violate zoning laws and hoarders will set up a rescue organization as a 501(c)(3) non-profit, and without regulatory oversight, the good intentions can get out of hand. (1) 
In areas where laws do exist to protect animals they come from varying levels of government: at the state, county, or city ordinance level. The laws vary from state to state and from city to city and where the laws do exist for regulating rescues the responsibilities fall to animal welfare inspectors, which is problematic mostly due to the lack of inspectors. For example, in Georgia there are 19 inspectors expected to cover 159 counties, while in Colorado the latest report released in 2012 from Pet Animal Care Facilities indicated they only had 4 inspectors for the whole state (Illinois Compiled Statutes,1).

A lack of enforced animal welfare industry standards and regulations by government has created a loophole for unethical rescues and sanctuaries to operate legally. This allows rescue hoarders to continue taking in more animals while living conditions worsen and many times this is occurring while members of the community donate money and resources under the impression it is an ethical rescue. One such example is the 2008 hoarding case of cats at Tiger Cat Ranch Sanctuary in Tarentum, PA., where the operator Linda Bruno had been hoarding domestic cats for years as people continued to send her their unwanted cats thinking their pets were going to a reputable rescue. Out of the roughly 7,000 cats the Tiger Ranch had taken in during a 14-month period only 23 had been adopted out. When local law enforcement arrived on site they found horrific living conditions for the animals that were still alive, a situation all too common in animal hoarding case (Manning,2011). This case suggests that a high level of transparency, accountability, and responsibility are needed from animal rescue operators and addressing the lack of comprehensive standards of care in place for the animals is a first step. 


\section{Current Intervention Methods}

The limitations of the current intervention methods used with animal hoarders are examined in the book Animal Cruelty: A Multidisciplinary Approach to Understanding and much of the of difficulty stems from navigating issues such as personal freedom, private property, and mental competency. Unless others are being harmed most laws restrict intervening to protect individuals' civil rights. (Arluke, Patronek, 204) The intervention methods currently used with animal hoarders only focus on reacting to an already existing animal hoarder that has been identified rather than preventing and reducing the numbers of animal hoarding cases. The three intervention methods most commonly used against animal hoarders are:

1. criminal prosecution; may include fines, forfeiture of animals, and jail time;

2. civil suits and/or regulatory enforcement; and

3. mental health evaluations with subsequent treatment plans.

These methods are used once an animal hoarder has been identified. However, there are opportunities for consistent preventive measures which are discussed under Best Practices.

\section{Examining Criminal Intervention Methods}

Criminal interventions can pose issues because of two reasons: 1) the courts do not view hoarding as abuse, but as neglect, which carries a lighter punishment, and 2) the person on trial is generally found to not have intended harm to the animals ( HARC 21). Since most laws focus on the abuser's intentions towards the animals under their care, and because hoarding is classified as neglect rather than abuse, many hoarding cases are not prosecuted 
criminally in jurisdictions where laws are not specifically written to protect animals in hoarding cases. In Animal Cruelty: A Multidisciplinary Approach to Understanding, authors Arluke and Patronek describe the difficulty when trying to prosecute animal hoarders to the fullest extent of the law in some jurisdictions because of the issue of intent towards the animals in the hoarder's care. The authors report that the recent push for stronger penalties have only complicated the prosecution of hoarding cases further "Indeed, the recent attempt by many states to impose more serious penalties on abusers by classifying the intentional harm of animals as a felony crime may have unintentionally sidelined equally egregious cases of neglect with enormous suffering seen in hoarding cases"(Arluke, Patronek, 208).

At this time, the only two states to specifically outlaw animal hoarding are Hawaii and Illinois leaving the other 48 states with animal protection laws that do not sufficiently cover the complexities of animal abuse cases. It is rare for an animal hoarding case to be charged as cruelty and most of the time charges are added up because of pain and suffering on the part of humans in the situation as Arluke and Patronek write in Animal Cruelty: A Multidisciplinary Approach to Understanding:

When charges were filed, they tended to be for other problems like child endangerment or assault and battery of an investigating police officer. Guilty verdicts or no contest pleas were rare. If any sentence were passed, hoarders were ordered to give up animals, not get any more either temporarily or permanently, and/or stop breeding them. Occasionally, they were modestly fined or made to reimburse shelters for the cost of food and veterinary care. Jail time was rarely imposed except for contempt of court, fraud, and violation of probation. (209) 
When large hoarding cases are brought up in criminal court for prosecution the first challenge often is how many animals will be counted as most cases are counted as single acts of animal cruelty, no matter the number of animals in the case. There is serious risk of leading to high recidivism when these types of cases are not treated as seriously as abuse cases. In addition, there is a need for animal hoarders to be seen as having deliberate intention to obtain and maintain animals they cannot properly care for. Another dimension to criminal intervention is how the animals are handled once the criminal proceeding starts. Most of the time the animals, especially in large hoarding cases, are seized and held for weeks or months as evidence. This can create a real dilemma for the agents handling the care of the animals and most find themselves in a difficult situation of what is best for the animals in the end. The 2005 article "Long-Term Outcomes in Animal Hoarding Cases" exposes the struggle officials face when prosecuting animal hoarding cases:

In six cases, the officials expressed that they were caught between using the legal system to address the hoarding problem and doing what they believed was best for the animals. That is, officials were caught between a desire to prevent a return to the original hoarding situation and fear that the animals would languish in a shelter pending resolution of the court action. Consequently, the officials decided to either forego charges or push for plea-bargains, which would guarantee the hoarder a lesser charge in exchange for custody of the animals. (Berry,179)

Pitting the immediate needs of the animals against the long term punishment of the abuser results in higher emotional stress for the animals and a high rate of 
recidivism. This does not mean that criminal prosecution is not the correct intervention method to take with animal hoarders as many hoarders need vigorous prosecution, monitoring, and strict sanctions to discourage recidivism (HARC, 22).

\section{Examining Civil and Regulatory Intervention Methods}

Civil laws and regulatory interventions are another method for dealing with animal hoarders that may work in some cases where criminal intervention is not the appropriate method. Civil interventions retain the possibility of obtaining custody of the animals in the case much sooner than with criminal intervention by using civil forfeiture laws. Bonding laws were developed as civil forfeiture laws ${ }^{8}$ for animal cruelty cases and are usually incorporated into an existing criminal or civil statute (HARC, 22). Some bonding laws are limited by their defined applications and not all hoarding cases will fall under a state's defined bonding law protections, but for the states that do protect animals in hoarding cases the bonding law can help alleviate the financial burden on humane societies boarding the animals and the emotional burden on animals waiting to be adopted. Regulatory interventions also play an important role in addressing and preventing animal hoarding as municipalities or other local jurisdictions can enforce regulations on the local level with proper resources and a clear regulatory framework at the state,city, or local level. Local ordinances can be written to include protections for animals from hoarding cases and are faster to enact than legislation (HARC, 23). An example of an animal care ordinance can be found in Fort Wayne, IN where ordinance \#91.07 outlines the steps of removal and impoundment of animals thought to be in cruel, neglectful, or abusive situations. The animals are held at the Department of Animal Control for 5-7 days before 
the animal(s) becomes property of Animal Control. Animals deemed the legal property of the Department of Animal Control are subject to adoption or euthanization. This ordinance gives substantial power to Animal Control Officers to intervene in cruelty cases (HARC,35).

\section{Examining Mental Health Intervention Methods}

The role of mental health evaluations is recognized as a vital step by the animal welfare community to address the issues of animal hoarding and reduce recidivism, although the connection between mental health disorders and animal hoarding has not yet been fully studied. Since some hoarders display cognitive deficits that can be related to mental illnesses a comprehensive mental and neurophysiological examination must be conducted to evaluate any medical conditions (HARC, 23). Court ordered competency evaluations, short term involuntary commitments, and in-home assessments are all options for conducting mental health evaluations depending on the individual and the case. While these steps have the potential for incredible positive impact, the reality is there are many challenges when enacting these mental health interventions methods including, but not limited to the following:

- A majority of animal hoarders are low-income and/or on a fixed income which can present challenges when seeking mental health treatment sessions.

- Conducting and monitoring mandatory counseling for animal hoarders may be difficult to maintain as cutbacks and high caseloads are affecting the officials in charge of compliance (HARC, 25). 
There is a need for a multidisciplinary approach that includes preventive steps, mental health evaluations if need be, and criminal prosecution for persons found guilty of animal hoarding. Without a long-term plan and the proper resources and support the current evidence indicates that recidivism for animal hoarders is at $100 \%$ (Berry,173).

\section{Best Practices}

The best practices section represents many of the guidelines set out by The Humane Society of the United States, The Association of Shelter Veterinarians, and the well respected no-kill animal sanctuary in Utah, Best Friends Animal Sanctuary, for running an ethical animal rescue that does not result in overcrowding or neglect of the animals; in addition to examining the 2 states that include animal hoarding in their laws, Illinois and Hawaii. As this paper has established the legal paperwork required to start an animal rescue in the United States is minimal. Subsequently many professionals in the animal welfare world have advanced a number of Best Practices in an effort to reduce the establishment of future hoarding and neglect cases. An additional idea includes The 5 Freedoms, formulated in 2010 by the Association of Shelter Veterinarians, and can provide a philosophical basis for an ethically run animal rescue (4). These include:

1. freedom from hunger and thirst by ready access to fresh water and a diet to maintain full health and vigor;

2. freedom from discomfort by providing an appropriate environment including shelter and a comfortable resting area;

3. freedom from pain, injury or disease by prevention or rapid diagnosis and treatment; 
4. freedom to express normal behavior by providing sufficient space, proper facilities and company of the animal's own kind; and

5. freedom from fear and distress by ensuring conditions and treatment which avoid mental suffering.

While rescue hoarders might continue to offer some type of shelter and access to food/water, the overcrowded conditions cannot help but lead to neglect. The Humane Society of the United States reports one issues to consider when starting a shelter is that "Overcrowding often occurs when animals are taken in with no plan of exit (adoption/foster/euthanasia) and for the reasons just described, overcrowding results in cruelty. It is not enough to just provide bare minimums of food, water and shelter ..." (2). Since rescue hoarders inhabit a deep abhorrence for euthanasia the risk of overcrowding is very real and without a plan for placement the amount of animals will quickly escalate and the living conditions will decline, resulting in animal suffering.

The sensitive subject of humane euthanasia is a common topic in the animal welfare world and any ethically run animal shelter needs a meaningful and informed euthanasia policy. Best Friends Animal Society (BFAS) is a well respected no-kill animal shelter in Utah that provides many online resources for starting an animal rescue and touches on the need for all animal rescues to have a euthanasia policy in place. An issue in many rescue hoarding cases is the refusal from the hoarder to place any animals in homes or euthanize the animals that are suffering. Furthermore, as BFAS points out on their website all "Responsibly-run no-kill shelters provide humane euthanasia to animals who are suffering and beyond help. It's best to have a written policy in place regarding the standards for making the decision to euthanize an animal . . ." (11). BFAS also highlights the need for meeting the psychological and physical needs of the 
animals by providing a "cage-free environment". By providing these standards of care the 5 Freedoms listed above can be successfully achieved.

As previously stated, there are currently only two states with animal hoarding specific laws, Illinois and Hawaii. Because of the more comprehensive animal protections in place in Illinois, they have ranked as the \#1 state for animal protection laws eight years in a row by the Animal Legal Defense Fund (12). The Illinois Humane Care Animal Act passed in 2001 covers companion animal hoarders and mandates counseling for animal hoarders while the law provides increased penalties for repeat animal hoarders (13). Hawaii is the only state to specifically outlaw animal hoarding passing Senate Bill 3203 in 2008, making animal hoarding under the law a misdemeanor offense if the person is found guilty under the following circumstances:

(a) Possesses more than fifteen dogs, cats, or a combination of dogs and cats;

(b) Fails to provide necessary sustenance for each dog or cat; and

(c) Fails to correct the conditions under which the dogs or cats are living, where conditions injurious to the dogs', cats', or owner's health and well-being result from the person's failure to provide necessary sustenance (14). Combining state oversight and regulation with the 5 Freedoms as an ethical framework could create a healthy, holistic to animal rescue; one that is beneficial to the animals and one less likely to result in overcrowding and neglect. 


\section{Suggestions and Conclusion}

Animal hoarding is a complex social problem that requires a multidisciplinary approach with actors in public and animal welfare agencies working together. As previously reported by the ASPCA, there are nearly 2,000 new rescue hoarding cases annually which challenges us to reexamine the benefits of maintaining the status quo of the current intervention methods. Criminal interventions are vital to addressing rescue hoarders, but the lack of laws in most states make criminal difficult. Civil and regulatory regulations play an important role, but without comprehensive regulatory framework there are no legal avenues to obtaining custody of animals in a hoarding case. Mental health interventions are needed, but many professionals do not take animal hoarding seriously as a mental health disorder so many hoarders are not treated for their illness.

There is no one answer solution to reducing the rate and recidivism of animal hoarders, but there are many opportunities to address the underlying reasons for the high rate of animal hoarders. The Hoarding Animal Research Consortium recommends “ . . . steps which are intermediate between criminal justice and a purely therapeutic approach exist in others fields and should be considered for animal hoarding interventions" (HARC, 26). This multidisciplinary approach is critical to addressing animal hoarders because these cases cross many agencies including adult and child protective services, public health departments, and municipal code officials and the lack of standardized protocols between these agencies allows for a high recidivism rate. In the article "Long Term Outcomes in Animal Hoarding Cases", the authors offer some possible changes (188): 
- Revision of animal cruelty statutes to be more responsive to problems of neglect.

- Education of prosecutors and judges about the nature of animal hoarding and its consequences for the animals and people affected by it.

- Education of mental health, social services, and veterinary professionals about the nature of animal hoarding and the individuals involved.

- Better planning, communication, and coordination of all stakeholder agencies likely to be called upon to respond to hoarding situations.

Improved animal protection laws are needed and the Animal Legal Defense Fund offers some suggestions for areas to focus on including but not limited to (p.9-13):

- Stronger felony penalties for neglect, abandonment, and sexual assault

- Increased penalties for offenders with prior violent offenses

- Mandatory forfeiture of animals upon conviction with a court calendar when animals are in custody

- Broader law enforcement powers to humane agents to enforce animal protection laws

The education of mental health professionals on the seriousness of animal hoarding is imperative due to animal hoarding still not to be officially recognized as a Hoarding Disorder (HD) by the American Psychiatric Association (AMA) and by doing so will “ . . . change the territory considerably by engaging more mental health professionals and researchers in the care and study of this complex disorder" (Aluke, Patronek, 212). Currently the AMA only lists animal hoarding as condition associated with HD due to the lack of available evidence on animal hoarding as a mental health issue (15). The issues faced in criminal prosecutions of animal hoarders would also be reduced with proper mental health education about animal hoarding as 
judges and prosecutors could be educated about the impacts of animal hoarding on the community at large. While the current intervention methods focus on animal hoarding once it has reached a point of being out of control there are many opportunities for prevention. One of the first steps in preventive action is educating the general public about proper animal care and the signs to look out for if a rescue is overcrowded. There is also an opportunity to require certain levels of education and/or verifiable experience in order to be approved to operate a 501(c)(3) animal rescue. In addition to education, crafting laws based on the 5 Freedoms into state laws that could be enforced. Policies such as animal housing requirements, the number of animals taken in versus adopted out annually, a comprehensive euthanasia policy, and the ratio of staff/volunteers to animals are all areas of animal rescue work that are critically important to ensuring the animals thrive and that rescues do not end up overcrowded. These policies along with stronger legal ramifications for animal hoarders and more comprehensive education on animal hoarding as a mental health issue would aim to holistically address the complex community problem that is animal hoarding. 
Notes

1. HARC out of Tufts University formed in 1997 from a group of concerned professionals in the field of animal welfare to address the issue of animal hoarding. Contributors include Arnold Arluke, Professor of Sociology at Northeastern University and Senior Research Associate at the Tufts Center for Animals and Public Policy, and Colin Berry, Program Coordinator for The Humane Society of the United States. HARC's 2006 manual was published after researchers collaborated for 9 years to better understand animal hoarders.

2. Agencies includes, but is not limited to the following:

i. agencies working on behalf of animals

ii. local law enforcement

iii. health and mental health departments

iv. social services

v. code enforcement

vi. legal aid

vii. Department of Agriculture (HARC,4)

3. Animal Welfare Agencies is defined as:

i. Private humane societies with humane law enforcement agents

ii. Municipal animal care and control agencies

iii. Animal wardens

iv. National animal protection groups

v. Animal rights groups

vi. Animal rescue groups (HARC, 4)

4. Best Friends Animal Society is a no-kill animal sanctuary started in 2000 . Their mission is to Save Them All and they house on average 1,700 animals a day on their 20,000 acre sanctuary. All animals are either adopted out, cared for at the sanctuary for their entire lifetime, or humanely euthanized if deemed medically necessary. Best Friends is an active member in the animal welfare community and publishes content on their website specifically on combating pressing animal rights issues including hoarding and Breed Specific Legislation. 
5. The animal welfare community includes but is not limited to: people working within the above definition of animal welfare agencies, volunteers in the field of animal rescue work, concerned community members, and self-proclaimed animal rights advocates.

6. A broad term used for rescues that do not euthanize due to space or breed; rather the animal is housed until adopted out or naturally passes away.

7. Animal welfare inspectors are responsible for a broad range of duties depending on the state where they work, but examples from Georgia's Department of Agriculture website on the responsibilities of their inspectors include, but are not limited to:

I. inspecting pet dealers, pet and bird breeders, bird dealers, and kennels taking appropriate regulatory action when guidelines are not met

II. inspecting animal shelters, taking appropriate regulatory action when guidelines are not met

III. conducting pre-license inspections of new establishments

IV. investigating complaints on establishments and/or animals in licensed facilities (Georgia Department of Agriculture, 2016)

8. Civil forfeiture is defined as "The involuntary relinquishment of money or property without compensation as a consequence of a breach or nonperformance of some legal obligation or the commission of a crime" (Forfeiture, 2016). 


\section{Works Cited}

Arluke, A., \& Patronek, G. (2013). Chapter 10: Animal Hoarding. In Animal cruelty: A multidisciplinary approach to understanding. Carolina Academic.

Berry, C., Lewis, B., Arluke, A., \& Frost, R. (2006). The Hoarding of Animals Research Consortium. Retrieved from http://vet.tufts.edu/hoarding/

Berry, C., Patronek, G., \& Lockwood, R. (2005). Long-term Outcomes in Animal Hoarding Cases. Animal Law Review at Lewis \& Clark Law School.

Best \& Worst Animal Protection Laws by State - Ranked \#1 - \#50 - Animal Legal Defense Fund. (2015). Retrieved from http://aldf.org/press-room/press-releases/2015-report-released-best-worst-animal-protection-law $\underline{\text { s-by-state-ranked-1-50/ }}$

Forfeiture. (n.d.). Retrieved from http://legal-dictionary.thefreedictionary.com/forfeiture

Francione, G. (1996). Animals as Property. Retrieved from https://www.animallaw.info/article/animals-property

Frost, R., Stekekee, G., Arluke, A., \& Patronek, G. (2015). The Hoarding of Animals: An Update. Retrieved from http://www.psychiatrictimes.com/addiction/hoarding-animals-update

Georgia Department of Agriculture. (n.d.). Retrieved from http://www.agr.georgia.gov/animal-protection-faqs.aspx

Hayes, V. (2010). Detailed Discussion of Animal Hoarding. Retrieved from https://www.animallaw.info/article/detailed-discussion-animal-hoarding\#s71

Illinois Compiled Statutes: Humane Care for Animal Act. (n.d.). Retrieved from http://www.ilga.gov/legislation/ilcs/ilcs3.asp?ActID=1717

Lockwood, R. (n.d.). Recognizing and Responding to Rescue Hoarders. Webinar presented in 2011 by ASPCA. Retrieved from http://aspcapro.org/webinar/2011-10-17-000000/recognizing-and-responding-rescue-hoarders 
Maloney, F. (2014, February 04). How to Start an Animal Sanctuary. Retrieved from http://bestfriends.org/resources/for-shelters-and-rescuers/how-start-animal-sanctuary

Manning, S. (2011, January 26). When animal rescuers become animal hoarders.

Retrieved from

http://www.nbcnews.com/id/38978396/ns/health-pet_health/t/when-animal-rescuers-become-ani mal-hoarders/\#.Vz_UkSMrlzY

Newbury, S., Blinn, M., \& Bushby, P. (2010). Guidelines for Standards of Care in Animal Shelters. The Association of Shelter Veterinarians.

Pariser, K. (2014). Detailed Discussion of the Laws Regulating Rescue and Foster Care Programs for Companion Animals. Michigan State University: Animal Legal and Historical Center.

Patronek, G. J. (1999). Hoarding of animals: An under-recognized public health problem in a difficult-to-study population. Public Health Reports, 114(1), 81-87. doi:10.1093/phr/114.1.81

Patronek, G., \& Ascione, F. R. (2008). The international handbook of animal abuse and cruelty: Theory, research, and application. West Lafayette, IN: Purdue University Press.

Pet Industry Market Size \& Ownership Statistics. (2016). Retrieved from http://www.americanpetproducts.org/press_industrytrends.asp 